\section{Hypoglycaemia and heart failure}

Sir,

The observation that severe hepatic congestion could be complicated by hypoglycaemia, ${ }^{1}$ has additional relevance to the management of heart failure with angiotensin converting enzyme inhibitors (ACE inhibitors) in Type II diabetics who are concurrently receiving sulphonylureas. According to one study, captopril increases the sensitivity to insulin by $11 \%$ in Type II diabetes. ${ }^{2}$ The consequence of enhanced insulin sensitivity may be the occurrence of hypoglycaemic episodes when this drug is co-prescribed with sulphonylureas. ${ }^{3}$ Theoretically, the risk of this complication may be increased in patients with severe hepatic congestion.

O.M.P. Jolobe

Tameside General Hospital, Fountain Street, Ashton-under-Lyne, Lancashire OL6 9RW, UK.

\section{References}

1. Drah, M. \& Ghose, R.R. Hypoglycaemia and heart failure. Postgrad Med J 1992, 68: 304.

2. Pollare, T., Lithell, H. \& Berne, C. A comparison of the effects of hydrochlorothiazide and captopril on glucose and lipid metabolism in patients with hypertension. N Engl J Med 1989, 321: 868-873.

3. Arauz-Pacheco, C., Ramirez, L.C., Rios, J.M. et al. Hypoglycaemia induced by angiotensin-converting-enzyme inhibitors in patients with non-insulin dependent diabetes receiving sulfonylurea therapy. Am J Med 1990, 89: 811-813.

\section{Diagnosis and treatment of lymphomatoid granulomatosis}

Sir,

The report by Torrelo et al. ${ }^{1}$ raises important points concerning the diagnosis and treatment of lymphomatoid granulomatosis (LYG) that require further clarification. The authors consider the histopathological features of an angiocentric proliferation of mainly benign cells, and a predominantly $\mathrm{T}$-helper phenotype to be sufficient to enable a diagnosis of LYG to be made.

The delayed recognition that LYG (and some other peripheral T-cell lymphomas) were in fact lymphomas was mainly a result of the prominent infiltrate of inflammatory cells and the frequent absence of an easily identifiable population of malignant lymphocytes. ${ }^{2}$ The malignant lymphoid cells in these lesions are often scanty and lack a homogenous appearance. ${ }^{3}$ An angiocentric pattern of lymphoid infiltrate is not a consistent feature of the so-called angiocentric lymphomas ${ }^{4}$ and is also not specific for this condition.

Studies showing clonal rearrangement of the beta T-cell receptor gene have confirmed that LYG is a malignant disorder. ${ }^{5}$ No conclusive phenotypic marker of T-cell malignancy is currently available but the aberrant expression of phenotypic markers is taken as a fairly reliable indicator of T-cell malignancy ${ }^{6}$ and reliable antibodies are available for the diagnosis to be made on paraffin-fixed tissue. ${ }^{7}$ Torrelo et al. ${ }^{1}$ have clearly not undertaken the minimum investigations required to establish the diagnosis of this uncommon lymphoma. This is of particular concern as the disease presentation in their patient was atypical.

The patient's disease progressed despite treatment with cyclophosphamide and prednisolone. In spite of his age and other symptoms (neuropathy, epistaxis and pulmonary disease), no further chemotherapy was administered. Long-term remissions have only been reported in $50 \%$ of patients treated with cyclophosphamide and prednisolone. ${ }^{8}$ The use of Adriamycin-containing chemotherapy regimens has produced long-term survivors amongst patients presenting with aggressive diease. ${ }^{9,10}$ This option should have been considered in this patient.

\section{S. Senan \\ Department of Radiation Oncology, University of Glasgow. Alexander Stone Building, Bearsden, Glasgow G61 1BD, UK.}

\section{References}

1. Torrelo, A., Martin, M., Rocamora, A., Allegue, F. \& Ledo, A. Lymphomatoid granulomatosis presenting as angioedema. Postgrad Med J 1992, 68: 366-368.

2. Jaffe, E.S. Pathologic and clinical spectrum of post-thymic T-cell malignancies. Cancer Invest 1984, 2: 413-426.

3. Suchi, T., Lennert, K., Tu, L.Y. et al. Histopathology and immunohistochemistry of peripheral $\mathrm{T}$ cell lymphomas: a proposal for their classification. J Clin Pathol 1987, 40: 995-1015.

4. Ho, F.C.S., Choy, D., Loke, S.L. et al. Polymorphic reticulosis and conventional lymphomas of the nose and upper aerodigestive tract: A clinicopathologic study of 70 cases and immunophenotypic studies of 16 cases. Hum Pathol 1990, 21: $1041-1050$.

5. Gaulard, P., Henni, T., Marulleau, J.P. et al. Lethal midline granuloma (polymorphic reticulosis) and lymphomatoid granulomatosis; evidence for a monoclonal T-cell lymphoproliferative disorder. Cancer 1988, 62: 705-710.

6. Picker, L.J., Weiss, L.M., Medeiros, L.J., Wood, G.S. \& Warnke, R.A. Immunophenotypic criteria for the diagnosis of non-Hodgkins lymphoma. Am J Pathol 1987, 128: 181.

7. Cabecados, J.M. \& Isaacson, P.G. Phenotyping of T-cell lymphomas in paraffin sections - which antibodies? Histopathology 1991, 19: 419-424.

8. Fauci, A.S., Haynes, B.F., Costa, J., Katz, P. \& Wolff, 'S.M Lymphomatoid granulomatosis: Prospective clinical and therapeutic experience over ten years. N Engl J Med 1982, 306: 60-74.

9. Drasga, R.E., Williams, S.D., Wills, E.R., Roth, L.M. \& Einhorn, L.H. Lymphomatoid granulomatosis: Successful treatment with CHOP combination chemotherapy. Am J Clin Oncol 1984, 6: 75-80.

10. Jenkins, T.R. \& Zaloznik, A.J. Lymphomatoid granulomatosis: A case for aggressive therapy. Cancer 1989, 64: $1362-1365$. 